Seashore disturbance and management of the clonal Arctophila fulva : Modelling patch dynamics

Rautiainen, $P$.

2004

http://hdl.handle.net/1975/7520

http://dx.doi.org/doi:10.1658/1402-2001(2004)007[0221:SDAMOT]2.0.CO;2

Downloaded from Helda, University of Helsinki institutional repository.

This is an electronic reprint of the original article.

This reprint may differ from the original in pagination and typographic detail.

Please cite the original version. 


\title{
Seashore disturbance and management of the clonal Arctophila fulva: Modelling patch dynamics
}

\author{
Rautiainen, P..$^{*}$; Laine, A.-L. .,3; Aikio, S. ${ }^{2,4}$; Aspi, J. ${ }^{1,5}$; Siira, J. ${ }^{1} \&$ Hyvärinen, M. ${ }^{1,6}$ \\ ${ }^{1}$ Department of Biology, University of Oulu, P.O. Box 3000, FIN-90014 Oulu, Finland; \\ ${ }^{2}$ Department of Biological and Environmental Sciences, University of Helsinki, P.O. Box 65, FIN-00014; Helsinki, \\ Finland; ${ }^{3} a n n a-l i i s a . l a i n e @ h e l s i n k i . f i ;{ }^{4}$ sami.aikio@helsinki.fi; ${ }_{5}$ jouni.aspi@oulu.fi; 6 marko.hyvarinen@oulu.fi \\ *Corresponding author; Fax +358 85531061; E-mail:pirjo.rautiainen@oulu.fi
}

\begin{abstract}
Question: What is the population viability of a critically endangered seashore grass, Arctophila fulva var. pendulina. Location: Liminka Bay, W Finland, 252 21'70 N, 6451'90 E. Methods: We constructed a matrix population model based on colonization and disappearance events and patch size changes of A. fulva. Patches were divided into hydric and nonhydric zones according to proximity to the seashore and intensity of disturbance. Perturbation analyses were carried out in order to identify transitions critical for population growth. Seed bank and seed germination studies provided background information for the model design.

Results: A. fulva patches observed in the more disturbed hydric zone (closest to the sea) increased in number, as did the total number of patches. However, the number of patches in the less disturbed non-hydric zone decreased.

Conclusions: Short-term dynamics of the A. fulva population at Liminka Bay seem to be determined by environmental fluctuations, which cause annual variation in transition rates between patch size classes. The long-term dynamics are probably governed by initiation of primary succession by isostatic land uplift. Increased disturbance at the water's edge may promote persistence of $A$. fulva through reduced interspecific competition. Our results suggest that shoreline disturbance of the hydric zone is sufficient for maintaining a viable population. Competitive exclusion of A. fulva in the non-hydric zone may be delayed by management practices, such as mowing.
\end{abstract}

Keywords: Arctophila fulva var. pendulina; Bothnian Bay; Hydric zone; Lefkovitch matrix model; Liminka Bay; Perturbation; Seashore.

Nomenclature: Hämet-Ahti et al. (1998).

Abbreviations: LTRE $=$ Life table response experiment; TTC = 2,3,5-triphenyl-2H-tetrazolium chloride.

\section{Introduction}

Seashores are dynamic environments where natural disturbances largely shape plant communities. Shores experience disturbance by waves, wind, water level changes, ice scouring and plant debris. Low stature meadows at the northernmost Baltic Sea coastline (Bothnian Bay) differ from oceanic shores in that the role of tidal disturbance and concomitant erosion is negligible, although water level changes may sometimes be considerable. In the Bothnian Bay ice scouring and floating plant debris destroy vegetation and debris also inhibits growth by blocking sunlight as documented for oceanic shores (Minchinton 2002), creating open habitats of low competitive pressure that enable plant establishment by seeds or clonal growth (Brewer et al. 1998). Water movement, ice and floating plant debris can also facilitate dispersal by seeds and plant fragments.

Disturbance may thus play a dual role in determining the plant population dynamics at low shores of the Bothnian Bay. Stochastic disturbances influence species interactions, composition and diversity and create areas at different successional stages. To understand how disturbances affect plant populations, it is necessary to study how population dynamics differ between areas of different disturbance regimes. Disturbances are of greatest intensity in areas near the water's edge, whereas the upper shore is less frequently and less intensively disturbed. Vegetation is also shaped by post-glacial isostatic land uplift (6.9 mm.yr ${ }^{-1}$ in the Oulu area; Anon. 2004) initiating primary succession.

Of 23 endangered Baltic shore plant species, half are specific to the open meadows (Ryttäri \& Kettunen 1997). Among these Arctophila fulva var.pendulina (Poaceae) is critically endangered (Rassi et al. 2001). A. fulva belongs to the Primula sibirica species group, which consists of seashore plant species that occur both along the coast of the Arctic Ocean and the Baltic Sea (Eurola 1999). On Baltic coasts these species' distributions are spatially fragmented and many are endangered. The 
species aggregate A. fulva has a circumpolar distribution but variety pendulina is endemic to the Bothnian Bay. The number of var. pendulina populations has declined over recent decades and only eight clearly separate, small populations remain in Sweden and Finland (Ericson \& Wallentinus 1979; Siira 1994). The largest population is at Liminka Bay (Fig. 1), where it covers an area of ca. 0.35 ha. Other populations range from a few square metres to some tens of square metres in area. Population declines may be due to changing agricultural practices: traditional cattle grazing and mowing that used to keep the seashores open have ended. Long-term data on water quality at Liminka Bay also indicates a pronounced eutrophication (Siira 1994) which, in addition to the effects of land uplift, has led to the demise of some species, including A. fulva (Markkola 1993).

A. fulva is a tall, perennial, clonal grass that usually grows as scattered monospecific patches in shallow water on the shores of seas, rivers and sometimes lakes (Väre 1997). It seems to prefer river estuaries and areas where competition with other species is limited. The life span of an individual aerial shoot is usually two years (Dobson 1989). The species flowers regularly, but no

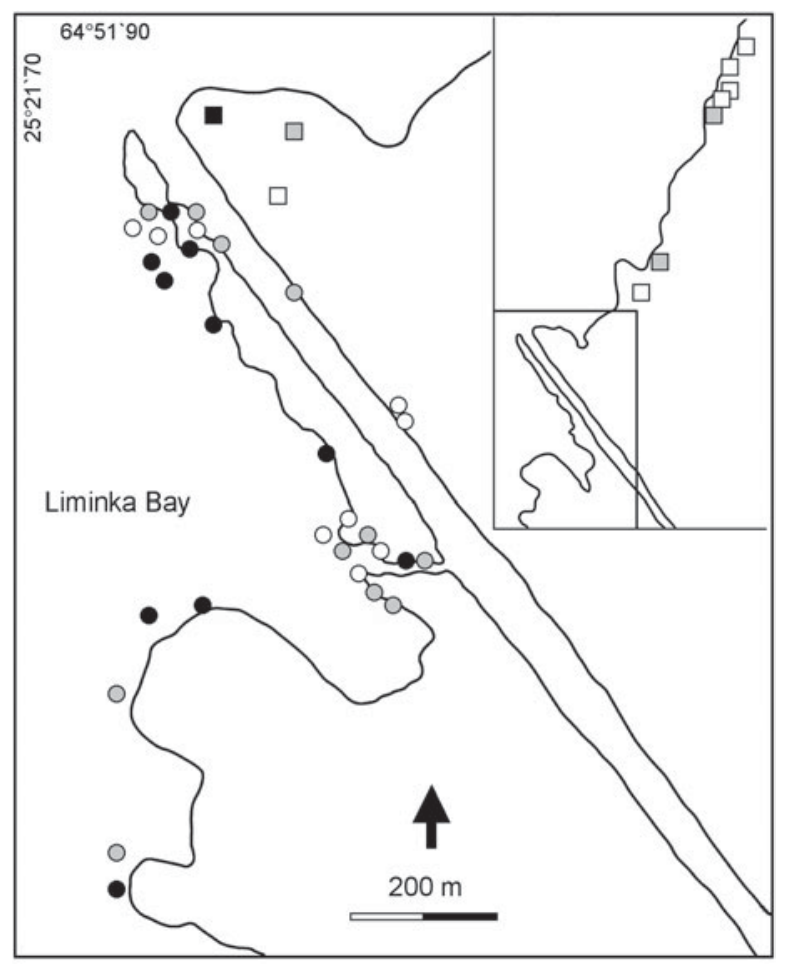

Fig. 1. Population of Arctophila fulva var. pendulina at Liminka Bay showing the patches of small (white), medium (grey) and large (black) size classes in hydric $(\bigcirc)$ and non-hydric $(\square)$ zones in 1999. seedlings have been found in the study area in $20 \mathrm{yr}$ (pers. comm.).

The aim of this study is to examine the dynamics and assess persistence of the A. fulva population at Liminka Bay. The biological information necessary for developing recovery guidelines for rare species includes an assessment of the biological status of the species and identification of life-history stages most critical to population growth (Schemske et al. 1994). Matrix population models offer a tool for assessing both of these and they have been widely used in conservation ecology (see e.g. García 2003; Lindborg \& Ehrlén 2002; Menges 1990; Rae \& Ebert 2002). Usually, an individual plant or shoot is used as the basic unit in population modelling. However, many seashore plants are clonal perennials with densely crowded shoots, and following individual shoot dynamics is difficult or impossible. We used an alternative approach, creating a matrix model based on A. fulva patch size classes to assess the status of the population and to recognise the stages of patch development that are most critical to growth and persistence of the species (Ehrlén 1999). We also assessed effects of contrasting disturbance and competition regimes on dynamics of populations in the closed vegetation of the upper shore and in the proximity of the water's edge. Seed bank and seed germination studies provided background information for the model design. The results of this study will be used to direct further research and to gain a better understanding of the net effect of shoreline processes on plant populations in seashore habitats.

\section{Material and Methods}

\section{Seed germination and seed bank experiment}

Spikelets of A. fulva were collected from six randomly chosen patches on 16 August and 3 September 1998. Spikelets collected in August appeared to contain mature yet undispersed seeds, whereas the ones collected in September were empty. Hence, it was concluded that seeds matured and dispersed in August. It was assumed that seeds undergo natural cold stratification before germination the next growing season. Seeds were stored in dry conditions and underwent ambient temperature conditions of the winter 1998-1999 prior to the germination experiment in 1999. Seeds were incubated on wet filter paper in six Petri dishes (50 seeds per dish) at $+20^{\circ} \mathrm{C}$ and a 16:8 light:dark cycle for eight weeks and checked for germinated seeds every five days. At the end of the experiment ungerminated seeds were dissected and placed in a $1.0 \%$ solution of $2,3,5-$ triphenyl-2H-tetrazolium chloride (TTC) to check their viability (Baskin \& Baskin 1998). Colour reaction of 
seeds was checked after 30 min, one and six hr. In 1999 seeds were collected from the field on 29 July, 9 August and 13 August. They were dissected and examined microscopically. Viability of collected seeds was checked using the TTC test described above.

To assess the seed bank, soil samples were taken from three patches (two large and one medium) surveyed since 1992. Samples were collected on 1 June. From each patch five soil samples were collected in PVC cylinders (depth $25 \mathrm{~cm}$, diameter $10.3 \mathrm{~cm}$ ). Samples were divided vertically into $5 \mathrm{~cm}$ layers which were homogenised and $10 \mathrm{~mm}$ of soil was placed in a Petri dish. Samples were kept in a growth chamber at a temperature of $+20^{\circ} \mathrm{C}$ and a 16:8 light:dark cycle for eight weeks. They were watered ca. every three days. After eight weeks seedlings were identified and removed from the samples, which were again subjected to cold stratification (seven days at $-3^{\circ} \mathrm{C}, 28$ days at $-18^{\circ} \mathrm{C}$ and seven days at $-3^{\circ} \mathrm{C}$ ). After this samples were placed in the growth chamber for another eight weeks and checked again for seedlings.

\section{Census data and the projection matrix model}

The area and location of all patches of A. fulva at Liminka Bay were assessed at the end of every growing season (August-early September) from 1992 to 1999. The patches were classified by area as: small $\left(<20 \mathrm{~m}^{2}\right)$, medium $\left(20-99 \mathrm{~m}^{2}\right)$ or large $\left(>99 \mathrm{~m}^{2}\right)$. More size classes were considered, but increasing the number of size classes would have resulted in many zero transition probabilities. The annual patch survival and transitions between size classes (Fig. 2) were used to construct $3 \times$ 3 transition matrices following Lefkovitch (1965). Annual probabilities of new patch formation, patch survival in a size class, or growth or decrease to another class, were calculated from field census data. New patches were assumed to have originated from the nearest existing patch.

The population was divided into two subpopulations based on position relative to the shoreline. Patches nearest the water's edge in the hydrolittoral, where plants have plenty of open area for colonization but experience stochastic disturbance by wave action, plant debris and ice scouring, were assigned to the hydric zone subpopulation. Patches further from the water, in the lower geolittoral or upper shore, where the vegetation is dense and more continuous, were assigned to the non-hydric zone subpopulation. In the non-hydric zone, surrounding vegetation and distance from the shoreline reduce the force of the waves and plant debris rarely reaches the area.

Census data yielded seven inter-annual transition matrices for the population as a whole and the hydric and non-hydric habitat zones separately. Mean transition rates and standard deviation SD were calculated from these matrices. Elasticities were used to identify the transitions that are the most effective management targets. The elasticities sum to unity across the whole matrix and represent the relative contribution of each matrix element to the population growth rate (Horvitz et al. 1997). Elasticities indicate the relative importance of life cycle transitions for population growth and maintenance (de Kroon et al. 2000). We quantified the contribution of transition rates to the differences between population growth rates in the hydric and non-hydric zones by analysing the difference between hydric and non-hydric zones as a fixed-design life table response experiment (LTRE; Caswell 1996, 2001). With LTRE analysis we studied which transitions contribute most to the differences between growth rates of the two different subpopulations. The eigenvalue sensitivities of this analysis were calculated from the transition rate matrix that was a mean of the matrices for the hydric and nonhydric zones.

Patch numbers for the whole population were simulated over $20 \mathrm{yr}$ by randomly choosing one of the seven transition rate matrices for each year and using it for projecting population densities in the next year. The simulations were replicated $1000 \times$ to obtain a mean and s.d. for the simulated number of patches. Extinction probabilities at the whole population and hydric and non-hydric zones were based on $200 \mathrm{yr}$ stochastic simulations with 10000 replicates, the extinction probability being estimated as the portion of simulations leading to population extinction. Transition matrices were randomly picked from the seven observation based matrices and results for each simulated year were rounded down to the nearest whole number. Matrix analyses and population simulations were performed with Matlab 5.2 [Matlab 5.2. (The MathWorks Inc., 24 Park Way. Natick, MA 01760 USA)].

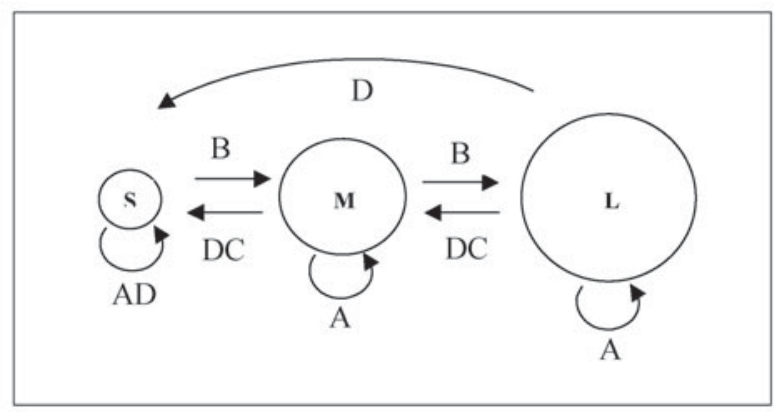

Fig. 2. Life cycle graph for the population of Arctophila fulva at the Liminka Bay. Arrows indicate transitions among patch size classes: (S) small, (M) medium and (L) large. Transitions between patch classes are: (A) survival in the same size class, (B) growth to a larger size class, (C) shrinkage to smaller size class and (D) production of a new patch. 


\section{Results}

\section{Seed germination and seed bank experiment}

Seeds collected in the summer of 1998 did not germinate and showed no respiration when tested with TTC indicating that the seeds were not viable. Seeds collected in 1999 showed no respiration either and, under microscopic examination, only $10 \%$ contained endosperm and none contained embryos. Soil samples in the seed bank experiment did not produce any A. fulva seedlings, even though seedlings of several other species, living in similar conditions, appeared, and we concluded that A. fulva does not have a reserve of viable seeds in the soil.

\section{Projection matrix model}

Altogether, there were 50 patches at Liminka Bay during the study period, 32 in the hydric zone and 18 in the non-hydric zone. The large patch size class was very

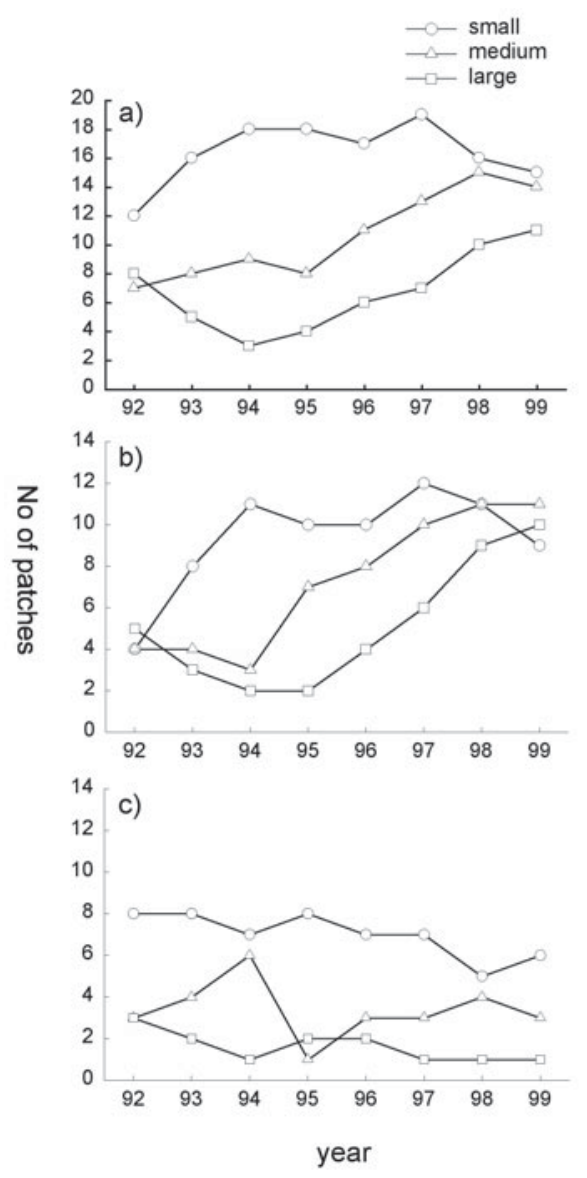

Fig. 3. The observed number of patches in the three categories, small, medium and large, from 1992-1999. The graphs are drawn for (a) the whole population and population data divided into (b) the hydric and (c) non-hydric zones. stable, as none of them disappeared during the eight year study period. Of nine patches that disappeared, seven were in the small and two in the medium size classes. Patch number increased in the hydric zone during the survey period and decreased in the nonhydric zone (Fig. 3). New patches were formed near existing ones: $91 \%$ were within 1-20 m of existing patches suggesting short dispersal distances. Eight of nine patch extinctions occurred in the non-hydric zone and $70 \%$ of new patches were established in the hydric zone.

When all patches of the Liminka Bay area were pooled, population growth rate, measured as the dominant eigenvalue $\lambda=1.054$ of the mean transition rate matrix, suggested that the number of patches is increasing. The stochastic simulation with the seven transition matrices showed an increasing number of patches in the hydric zone $(\lambda=1.14$, Fig. 4$)$, while the patch number decreased in the non-hydric zone $(\lambda=0.96$, Fig. 4$)$. The expected rates of change in patch numbers obtained from stochastic simulations equal the geometric mean of dominant eigenvalues of the seven transition matrices. The annual variation in the eigenvalues was three times greater in the hydric $-\operatorname{SD}(\lambda)=0.145$ - than in the non-hydric zone $-\operatorname{SD}(\lambda)=0.054$. When patches of both zones were pooled, $\lambda$ varied little $-\mathrm{SD}(\lambda)=0.057-$ and the most variable transition turned out to be the shrinkage from large to medium patch size (Table 1).

The elasticity analysis showed the growth of the pooled population to be most sensitive to the changes in the transition small to small which includes both the probability of small patches staying small or small patches producing new small patches (Table 1). The division of the population into hydric and non-hydric zones did not change the result much: the probability of staying in the small class still had the highest elasticity, but the probability of staying in the large size class now seems to be more important in the hydric than in the non-hydric zone (Table 1).

The LTRE resulted in the following contributions of each transition for the difference between hydric and non-hydric zones:

$C_{92-99}=\left[\begin{array}{ccc}-0.0081 & 0.0463 & 0.0164 \\ 0.0816 & -0.0210 & -0.0207 \\ 0 & 0.0557 & 0.0284\end{array}\right]$

Positive values indicate transitions that increase the growth rate at the hydric zone compared to the nonhydric zone, while negative values indicate the opposite. The difference in the mean matrix dominant eigenvalues between the hydric and the non-hydric populations was $\lambda_{\text {hydric }}-\lambda_{\text {non-hydric }}=0.18$, which approximates the sum of LTRE contributions (0.1786) (see 
Table 1. Transition rates between small, medium and large patch size classes expressed as the mean of seven annual transition rate matrices. Corresponding elasticities and annual variation of transition values for the means of seven matrices of Arctophila fulva from 1992-1999 are also shown. Transitions for the whole population are given in bold.

\begin{tabular}{|c|c|c|c|c|c|c|c|c|c|}
\hline \multirow[b]{2}{*}{ From: } & \multicolumn{3}{|c|}{ Annual transition rates } & \multicolumn{3}{|c|}{ Elasticities } & \multicolumn{3}{|c|}{ SD } \\
\hline & Small & Medium & Large & Small & Medium & Large & Small & Medium & Large \\
\hline \multicolumn{10}{|l|}{ To: } \\
\hline Small & 0.83 & 0.29 & 0.12 & 0.30 & 0.06 & 0.02 & 0.11 & 0.15 & 0.18 \\
\hline hydric & 0.82 & 0.38 & 0.18 & 0.30 & 0.09 & 0.02 & 0.11 & 0.36 & 0.28 \\
\hline non-hydric & 0.84 & 0.23 & 0 & 0.52 & 0.07 & 0 & 0.19 & 0.25 & 0 \\
\hline Medium & 0.18 & 0.69 & 0.18 & 0.09 & 0.21 & 0.03 & 0.11 & 0.12 & 0.20 \\
\hline hydric & 0.23 & 0.70 & 0.16 & 0.11 & 0.22 & 0.03 & 0.14 & 0.18 & 0.22 \\
\hline non-hydric & 0.09 & 0.75 & 0.33 & 0.07 & 0.30 & 0.01 & 0.13 & 0.30 & 0.37 \\
\hline Large & $\mathbf{0}$ & 0.13 & 0.80 & $\mathbf{0}$ & 0.05 & 0.22 & $\mathbf{0}$ & 0.12 & 0.17 \\
\hline hydric & 0 & 0.15 & 0.87 & 0 & 0.05 & 0.17 & 0 & 0.16 & 0.17 \\
\hline non-hydric & 0 & 0.02 & 0.67 & 0 & 0.01 & 0.02 & 0 & 0.06 & 0.37 \\
\hline
\end{tabular}

Caswell 1996). The growth from small to medium sized patch explains most of the variation in growth rates between the two zones, but the transition from medium to large patch and production of small patches by medium
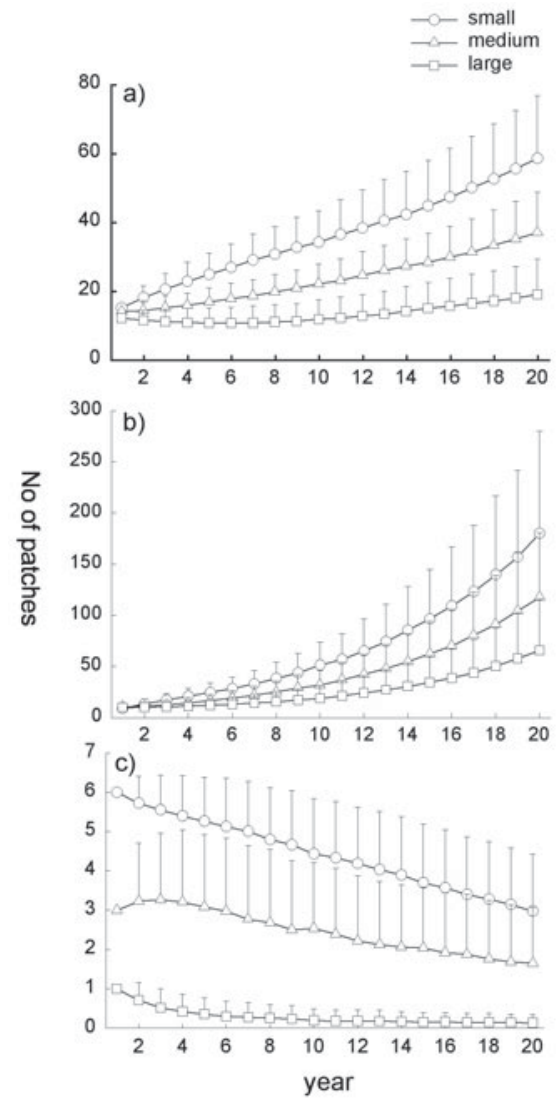

Fig. 4. The number of patches as predicted by the stochastic simulation (mean \pm SD of 1000 simulations) for (a) the whole population, (b) the hydric and (c) non-hydric zones separately. The annual population growth rates that correspond to the mean of stochastic simulations are: whole population $=1.054$, $\lambda_{\text {hydric }}=1.14$ and $\lambda_{\text {non-hydric }}=0.96$. sized patch also made a large contribution to the difference between the $\lambda$-values for the two zones.

According to the stochastic simulation the cumulative extinction probability of the whole population is low, only ca. $4.5 \%$ in $150 \mathrm{yr}$ (Fig. 5). When analysed separately, the hydric zone yields zero extinction probability, whereas the non-hydric zone is expected to become extinct within $40 \mathrm{yr}$ (Fig. 5). The median time to extinction in the non-hydric zone is ca. $25 \mathrm{yr}$.

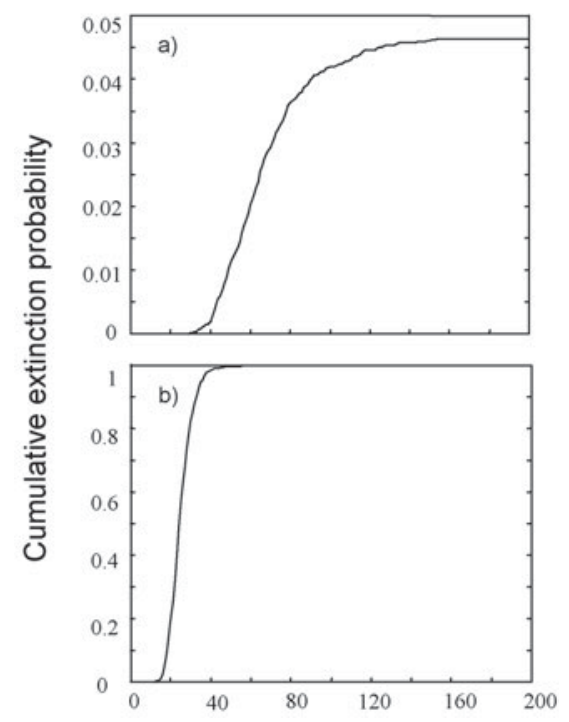

Fig. 5. The cumulative extinction probabilities over $200 \mathrm{yr}$, calculated as the proportion of 10000 stochastic simulations that lead to population extinction. The panels show the extinction probabilities for (a) the whole population and (b) the nonhydric zone. Note the different scales of the $y$-axes. The extinction probability was zero in the hydric zone. 


\section{Discussion}

Although A. fulva flowers regularly, lack of viable seeds and seed bank indicate sexual reproduction to be unsuccessful. This may be a common phenomenon among seashore plants (Harrison 1979; Ramage \& Schiel 1999). Bouzillé et al. (1997), for example, found no Juncus gerardii seedlings in western France despite regular flowering. Dispersal and colonization of A. fulva apparently occur mainly vegetatively through clonal growth from rhizomes. Ice scouring and floating debris loosen shoots and rhizome fragments which may root and form new patches (Rautiainen et al. unpubl.). In arctic Canada A. fulva is often sterile and propagates vegetatively (Porsild 1957) and is even able to grow new shoots from the previous season's, apparently dead, stems (Aiken \& Buck 2002).

Colonization events in the present study show that although dispersal by rhizomes does occur at Liminka Bay, it appears to be limited to small distances from existing patches. Therefore, it is appropriate to assume that the most likely origin of a newly formed patch is the nearest existing one. Differences in patch formation and disappearance supported the division of the population into two zones. Only one of the patches that disappeared and most of the new patches were in the hydric zone.

Despite the critically endangered conservation status of the species, the Liminka Bay population of $A$. fulva does not seem to be in immediate danger of extinction. According to the mean transition rate matrix analysis for the whole population, the number of patches was increasing. Stochastic simulations on the seven interannual transition matrices showed that the hydric zone population near the seashore is not likely to become extinct. The situation is more worrisome for the nonhydric zone, however, since the number of patches in that zone is decreasing and expected to lead to extinction within the next $40 \mathrm{yr}$.

The higher growth rate in the hydric zone compared to the non-hydric one was mostly due to the former having a higher patch growth rate from small to medium patch size class. This is probably due to stronger effects of interspecific competition on A. fulva in the non-hydric zone. Small patches are more likely to be outcompeted by other species in the non-hydric zone. Disturbance by ice scouring does not seem to be sufficient in the non-hydric zone to create open gaps suitable for A. fulva colonization and to slow competitive displacement of A. fulva by later successional species. The hydric, early successional environment is characterized by the opposite: interspecific competition is low in intensity and frequent and intense disturbances leave ample space for colonization. This is similar to the dynamics of Pedicularis furbishiae in St. John
River Valley in northern Maine (USA), where river dynamics both cause mortality and create a habitat for colonization (Menges 1990).

The populations of both hydric and non-hydric zones exhibited little annual variation in the rate of increase in the number of patches, although variation was higher in the hydric zone, implying that the transitions with lowest elasticities were least variable between years and some transition rates were negatively correlated. This means that extinction events were balanced out by colonizations, a common observation for many other plant species (Silvertown \& Lovett Doust 1993). For example, 1995 was characterized by storms and rapid changes in the sea level and these frequent disturbances led to the highest extinction rates observed during the survey period, as well as the highest rate of establishment of new patches.

Variation in demographic parameters includes demographic stochasticity and sampling effect, systematic differences between populations, and environmental variability (de Kroon et al. 2000). We consider that the observed variation in the A. fulva population size is mainly due to variation in the environment. Moreover, transition rates differ in variability: shrinkage of large patches to medium patches had the highest variance. Due to the longevity of clones and other remnant qualities, sensu Eriksson $(1996,2000)$, such as clonal propagation, the persistence of patches in the large size class could ensure population survival in the landscape for long periods and should not be ignored when conservation measures are outlined.

In all analyses, population growth rate was most affected by persistence of small patches within their size class or the production of new small patches. The survival of small patches depends on environmental disturbances. As A. fulva seems to be a poor competitor for space, it needs gaps created by disturbance in the non-hydric zone for colonization. In turn, disturbance creates new patches by dispersing rhizome fragments in the hydric zone.

While environmental fluctuations appear to drive short-term population dynamics of A. fulva, primary succession caused by isostatic land uplift is the main deterministic force influencing A. fulva population dynamics. It seems that the frequently disturbed parts of $A$. fulva habitats are able to maintain viable populations and do not require special management. Isostatic land uplift moves $A$. fulva patches further away from the shore in the non-hydric zone where competition, due to soil eutrophication and the absence of man made or natural disturbance, may lead to extinction (Siira 1994). The longevity of A. fulva genets may ensure the persistence of extant patches for a long time, but cannot change the inevitable successional progress that leads to disappearance. 
Although the population of A. fulva at Liminka Bay is not in immediate danger of extinction, it should be carefully monitored in the future. Generally, marginal populations of species with disjunct distributions are more sensitive to environmental variation than more continuous, central populations of the same species (Bengtsson 2000; Hunter 2002). Management can potentially maintain the population size high enough to avoid extinction due to an unpredictable disturbance event of great magnitude. For example, hay mowing around populations could slow down the process of other, more aggressive, species closing in on A. fulva patches. Removal of surrounding vegetation must, however, be carefully planned because water deposits more floating debris in sites where vegetation is either absent or low, potentially suffocating A. fulva patches (Rautiainen et al. unpubl.). In the long-term, persistence of the endemic flora of the Bothnian Bay area will only be ensured by targeting management efforts at a regional level. Revitalizing traditional agricultural methods, such as cattle grazing in the non-hydric zone, could help to conserve the unique vegetation of the Liminka Bay area.

Acknowledgements. We would like to thank J. Tuomi and P. Rautio for their invaluable comments on the manuscript. The research was supported by the Academy of Finland (projects \#47973 and 78130) and the Maj and Tor Nessling Foundation.

\section{References}

Anon. 2004. Keskiveden vaihtelut. Variation in mean water level (in Finnish). http://www2.fimr.fi/fi/tutkimus/ tutkimusalueet/fysikaalinen-tutkimus/v edenkorkeudenvaihteluiden-ajalliset-muutokset/keskiveden-vaihtelut. html

Aiken, S.G. \& Buck, R.A. 2002. Aquatic leaves and regeneration of last year's straw in the arctic grass, Arctophila fulva. Can. Field Nat. 116: 81-86.

Baskin, C.C. \& Baskin, J.M. 1998. Seeds: ecology, biogeography, and evolution of dormancy and germination. Academic Press, San Diego, CA, US.

Bengtsson, K. 2000. Long-term demographic variation in range-margin populations of Gypsophila fastigiata. Folia Geobot. 35: 143-160.

Bouzillé, J.B., Bonis, A., Clément, B. \& Godeau, M. 1997. Growth patterns of Juncus gerardi clonal populations in a coastal habitat. Plant Ecol. 132: 39-48.

Brewer, J.S., Levine, J.M. \& Bertness, M.D. 1998. Interactive effects of elevation and burial with wrack on plant community structure in some Rhode Island salt marshes. $J$. Ecol. 86: 125-136.

Caswell, H. 1996. Analysis of life table response experiments II. Alternative parametrizations for size- and stage-structured models. Ecol. Model. 88: 73-82.
Caswell, H. 2001. Matrix population models - Construction, analysis and interpretation. 2nd ed. Sinauer, Sunderland, MA, US.

de Kroon, H., van Groenendael, J. \& Ehrlén, J. 2000. Elasticities: A review of methods and model limitations. Ecology 81: 607-618.

Dobson, J.L. 1989. Autecology of aquatic and terrestrial growth forms of Arctophila fulva, an arctic tundra grass of northern Alaska. Ph.D. Thesis. University of Idaho, Moscow, ID, US.

Ehrlén, J. 1999. Modelling and measuring plant life histories. In: Vuorisalo, T.O. \& Mutikainen, P.K. (eds.) Life history evolution in plants, pp. 27-61. Kluwer, Dordrecht, NL.

Ericson, L. \& Wallentinus, H.G. 1979. Sea-shore vegetation around the Gulf of Bothnia. Guide for the International Society of Vegetation Science, July-August 1977. Wahlenbergia 5: 1-142.

Eriksson, O. 2000. Functional roles of remnant plant populations in communities and ecosystems. Global Ecol. Biogeogr. 9: 443-449.

Eriksson, O. 1996. Regional dynamics of plants: a review of evidence for remnant, source-sink and metapopulations. Oikos 77: 248-258.

Eurola, S. 1999. Kasvipeitteemme alueellisuus. Biogeography of Finnish Plants (in Finnish). Oulanka Reports 22, Oulu, FI.

García, M.B. 2003. Demographic viability of a relict population of the critically endangered plant Borderea chouardii. Conserv. Biol. 17: 1672-1680.

Harrison, P.G. 1979. Reproductive strategies in intertidal populations of two co-occurring seagrasses (Zostera spp.). Can. J. Bot. 57: 263-268.

Horvitz, C., Schemske, D.W. \& Caswell, H. 1997. The relative "importance" of life-history stages to population growth: prospective and retrospective analyses. In: Tuljapurkar, S. \& Caswell, H. (eds.) Structured-population models in marine, terrestrial, and freshwater systems, pp. 247-271. Chapman \& Hall, London, UK.

Hunter, Jr., M.L. 2002. Fundamentals of conservation biology. 2nd ed. Blackwell Science, London, UK.

Hämet-Ahti, L., Suominen, J., Ulvinen, T. \& Uotila, P. 1998. Retkeilykasvio. Field Flora of Finland (in Finnish). Yliopistopaino, Helsinki, FI.

Lefkovitch, L.P. 1965. The study of population growth in organisms grouped by stages. Biometrics 21: 1-18.

Lindborg, R. \& Ehrlén, J. 2002. Evaluating extinction risk of a perennial herb: demographic versus historical records. Conserv. Biol. 16: 683-690.

Markkola, J. 1993. Perämeren niityt ja niiden suojelu. Meadows of Bothnian Bay and their conservation (in Finnish). In: Marttila, O. (ed.) Avoimet perinneympäristöt osana suomalaista luontoa, hoito ja suojelu, pp. 12-15. EteläKarjalan allergia- ja ympäristöinstituutti, Lappeenranta, FI.

Menges, E.S. 1990. Population viability analysis for an endangered plant. Conserv. Biol. 4: 52-62.

Minchinton, T.E. 2002. Disturbance by wrack facilitates spread of Phragmites australis in a coastal marsh. J. Exp. Marine Biol. Ecol. 281: 89-107. 
Porsild, A.E. 1957. Illustrated flora of the Canadian Arctic Archipelago.Nat.Mus. Can.Bull. 146. National Museum Canada. Ottawa, CA.

Rae, J.G. \& Ebert, T.A. 2002. Demography of the endangered fragrant prickly apple cactus, Harrisia fragrans. Int. J. Plant Sci. 163: 631-640.

Ramage, D.L. \& Schiel, D.R. 1999. Patch dynamics and response to disturbance of the seagrass Zostera novazelandica on intertidal platforms in southern New Zealand. Marine Ecol. Progr. Ser. 189: 275-288.

Rassi, P., Alanen, A., Kanerva, T. \& Mannerkoski, I. (eds.) 2001. Suomen lajien uhanalaisuus 2000. The 2000 Red List of Finnish Species (in Finnish).Ympäristöministeriö \& Suomen ympäristökeskus, FI.

Ryttäri, T. \& Kettunen, T. 1997. Uhanalaiset kasvimme. Our Endangered Plant species (in Finnish). Suomen ympä- ristökeskus, Tammer-Paino Oy, Tampere, FI.

Schemske, D.W., Husband, B.C., Ruckelshaus, M.H., Goodwillie, C., Parker, I.M. \& Bishop, J.G. 1994. Evaluating approaches to the conservation of rare and endangered plants. Ecology 75: 584-606.

Siira, J. 1994. The occurrences and ecology of Arctophila fulva (Poaceae) on the Liminka Bay (The Gulf of Bothnia). Aquilo Ser. Bot. 33: 107-120.

Silvertown, J.W. \& Lovett Doust, J. 1993. Introduction to plant population biology. 3rd ed. Blackwell Science, Oxford, UK.

Väre, H. 1997. Pohjansorsimo. Pendant grass (in Finnish). In: Ryttäri, T.\& Kettunen, T. (eds.) Uhanalaiset kasvimme, p. 69. Suomen ympäristökeskus, Tammer-Paino Oy, Tampere, FI.

Received 23 September 2003; Accepted 20 June 2004. Co-ordinating Editor: K. Woods. 